Изв. АН Эстонии. Геол., 1990, 39, № 2, 41-49

удК $552.08: 53(474.2)+519.2$

Алла ШОГЕНОВА, Нгорь ТУУЛИНГ

\title{
ИЗМЕНЕНИЕ ФИЗИЧЕСКИХ СВОЙСТВ КАРБОНАТНЫХ ПОРОД В ЗОНЕ ТРЕЩИНОВАТОСТИ И ДОЛОМИТИЗАЦИИ (СЕВЕРНАЯ ЭСТОНИЯ)
}

Для изучения закономерностей изменения физических свойств карбонатных пород в зонах тектонических нарушений на Раквереском месторождении фосфоритьв было отобрано 140 образцов керна из 6 скважин, пробуренных через зону аномалии низкого сопротивления дипольного электропрофилирования, выявленную Р. Вахером (Шогенова, $1989 a$; рис. 1) и интерпретируемую как тектоническое нарушение III порядка - зона трещиноватости, осложненная карстовыми процессами и проседанием геологических слоев (Шогенова, 1989б, 1990) Скважины P-2279 и Р-2284 условно приняты за фоновые, так как породы,

Таблица 1

Статистические параметры распределения данных

\begin{tabular}{c|c|c|c}
\hline Переменная & $\begin{array}{c}\text { Количест- } \\
\text { во образ- } \\
\text { цов }\end{array}$ & $\begin{array}{c}\text { Мини- } \\
\text { мум }\end{array}$ & $\begin{array}{c}\text { Макси- } \\
\text { мум }\end{array}$
\end{tabular} \mid Среднее $\mid \begin{gathered}\text { Стандарт- } \\
\text { ное откло- } \\
\text { нение }\end{gathered}$

Нерастворимый остаток, \%

Доломитность

(дол $=\frac{\mathrm{MgO}}{\mathrm{CaO}+\mathrm{MgO}}$ )

Әффективная пористость

W, \%

Плотность сухих образцов

$\sigma_{\mathrm{C}}, \Gamma / \mathrm{cm}^{3}$

Плотность водонасыщенных образцов $\sigma_{\mathrm{B}}, \Gamma / \mathrm{cm}^{3}$

Структурно-минералогическая плотность $\sigma_{\mathrm{CM}}, \Gamma / \mathrm{cm}^{3}$

Скорость продольных волн в сухих образцах $V_{\mathrm{c}}, \mathrm{kм} / \mathrm{c}$ Скорость продольных волн в водонасыщенных образцах $V_{\mathrm{B}}, \mathrm{KM} / \mathrm{c}$

Магнитная восприимчивость

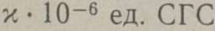

Остаточная намагниченность насыщения

$I_{r s} \cdot 10^{-6}$ ед. СГС

Кажущееся сопротивление

$\mathrm{QK}_{\mathrm{K}}, \mathrm{OM} \cdot \mathrm{M}$

136

94,44

19,54

14,54

136

129

0,02

0,42

0,21

0,15

129 1,58

21,55

7,41

4,25

129

2,07

2,81

2,58

0,15

2,20

2,84

2,62

0,12

129

130

2,40

2,94

2,74

0,709

1,44

6,24

4,36

0,89

112

2,83

6,52

4,97

0,87

141

0

45

7,25

8,82

140

5,85

5720

119,14

501,71

123

50

1312,5

363,3

243

$\eta$, \%

137
3,14

10,75

6,97

7,47

4,56

10,42

\section{1,34}

1,16
Дость $\varepsilon$ 

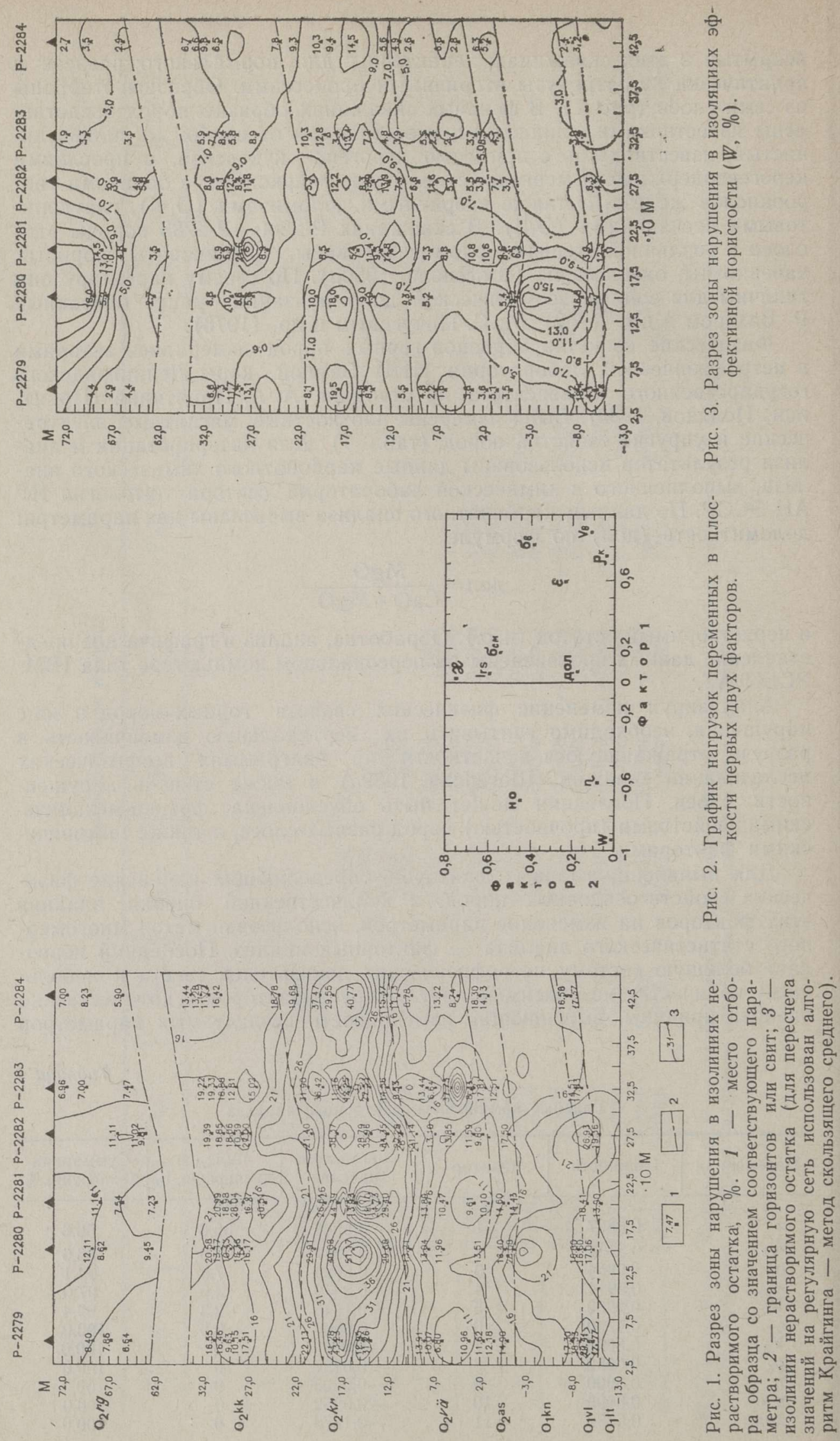

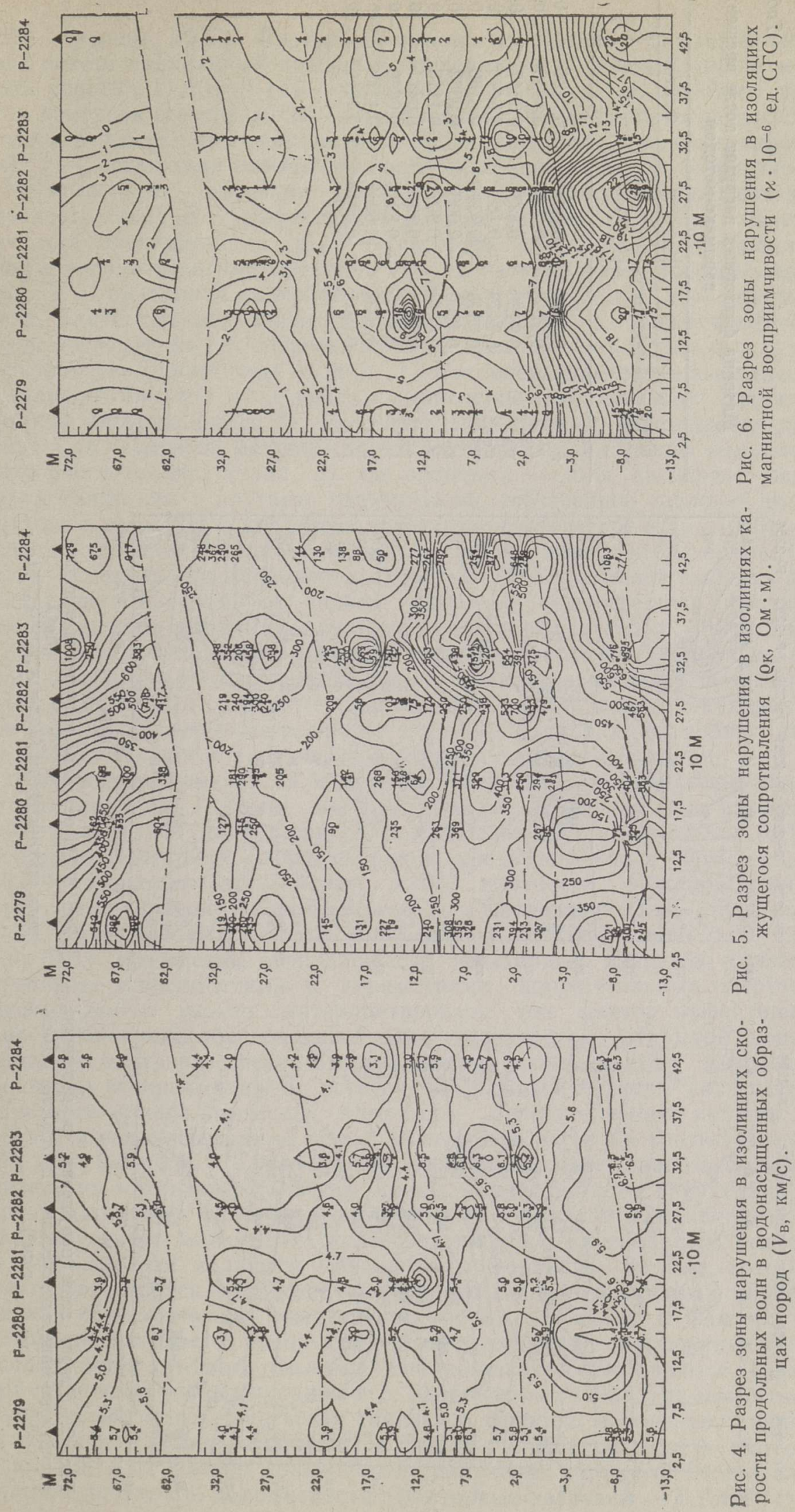


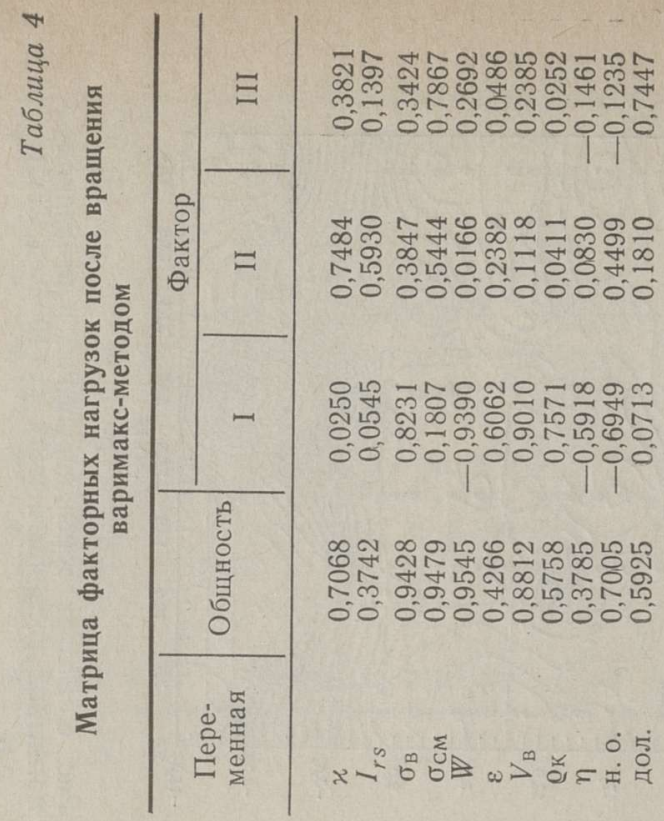
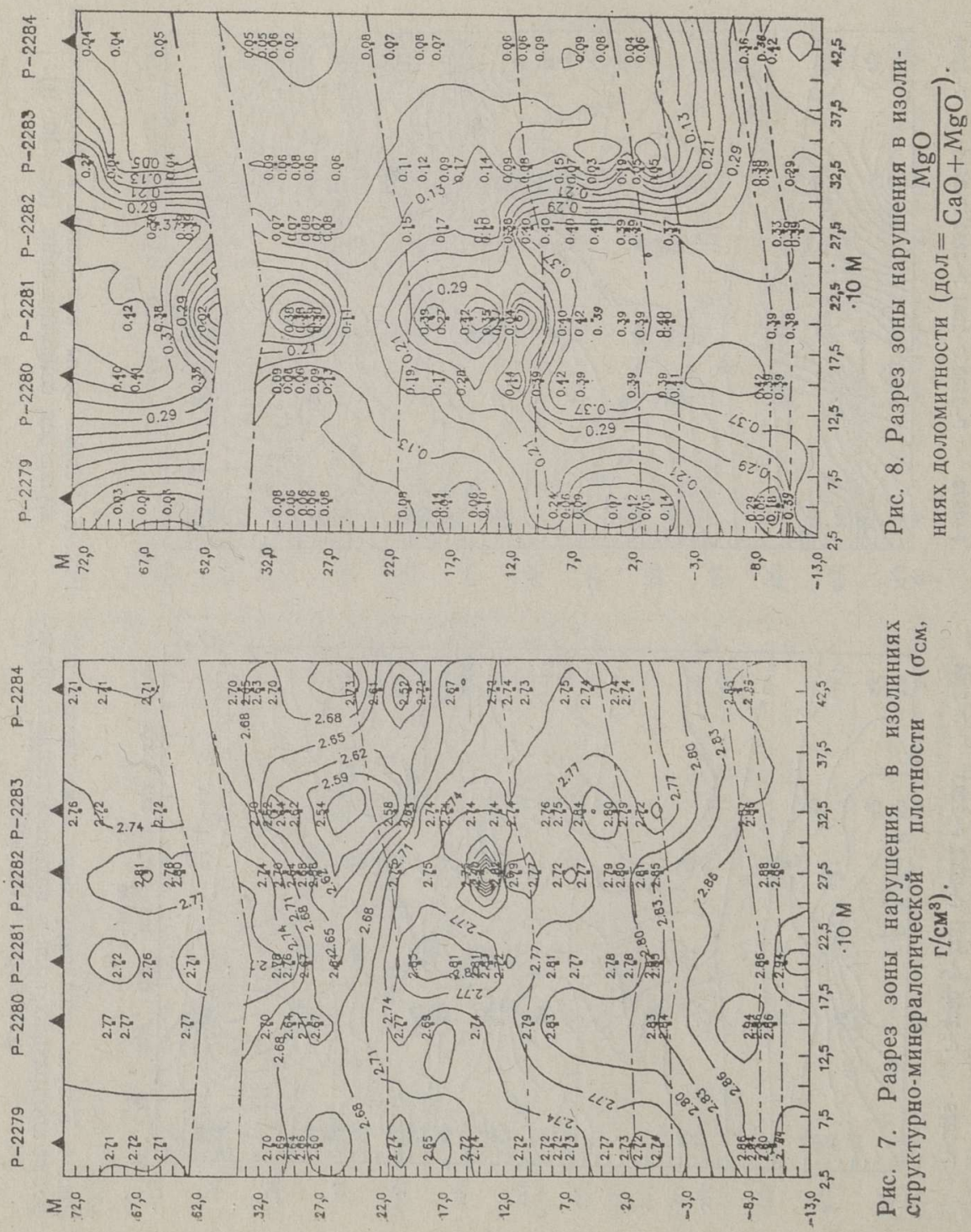
(Деч, Кноринг, 1978). Факторный анализ выполнен с помощью готового пакета прикладных программ. Исходными данными служила матрица порядка $11 \times 104$ (104 - количество образцов, по которым удалось измерить все параметры), составленная по следующим петрофизи= ческим и химическим параметрам: 1 - магнитная восприимчивость $(x), 2$ - остаточная намагниченность насыщения $\left(I_{r s}\right), 3$ - плотность водонасыщенных образцов $\left(\sigma_{\mathrm{B}}\right), 4$ - структурно-минералогическая плотность $\left(\sigma_{\mathrm{cM}}\right), 5$ - эффективная пористость в \% $(W), 6$ - диэлектрическая проницаемость $(\varepsilon), 7$ - скорость прохождения продольных волн в водонасыщенных образцах $\left(V_{\mathrm{B}}\right), 8$ - кажущееся сопротивление $\left(\varrho_{K}\right), 9$ - вызванная поляризация в \% $(\eta), 10-$ н. о., 11 - доломитность. Статистические параметры этих свойств, а также плотности сухих образцов $\left(\sigma_{\mathrm{c}}\right)$ и скорости прохождения продольных волн в сухих образцах $\left(V_{c}\right)$ приведены в табл. 1. Последовательность выполнения факторного анализа следующая: вычисление диагональной корреляционной матрицы (табл. 2), стандартизация данных, перемещение диагональных элементов матрицы, вычисление таблицы главных компонент факторного анализа (табл. 3), где общность - доля дисперсии параметра, связанная с другими параметрами, собственное число - вклад фактора в суммарную дисперсию параметров (Иёреског и др., 1980). Из таблицы главных компонент видно, что первые три фактора объясняют $94,1 \%$ изменчивости параметров (табл. 3). Это позволяет выбрать для дальнейшего анализа три первых наиболее существенных фактора, дающих вклад в дисперсию параметров соответственно 56,6; 30,0 и 7,5\%. С учетом этих факторов вычислена общность переменных, произведено вращение факторов варимакс-методом, вычислена матрица факторных нагрузок, построен график переменных в плоскости первых двух факторов (рис. 2). Полученные величины и их знаки (табл. 4) позволяют дать геологическую интерпретацию полученным факторам.

Наибольшее влияние на изменение физических и химических параметров оказывает I фактор. Он контролирует изменение семи параметров: эффективной пористости, н.о. и вызванной поляризации (отрицательные факторные нагрузки равны соответственно - 0,93 ; $-0,70$; -0,59), скорости продольных волн, плотности водонасыщенных пород, кажущегося сопротивления и диэлектрической проницаемости пород (факторные нагрузки равны соответственно 0,90; 0,82; $0,76 ; 0,61)$. Параметры отрицательных факторных нагрузок связаны обратными зависимостями с параметрами положительных нагрузок. Первый фактор можно интерпретировать как фактор эффективной пористости пород, обусловленной трещиноватостью, открытой пористостью и кавернозностью. Второй фактор контролирует изменения магнитной восприимчивости, остаточной намагниченности насыщения, структурно-минералогической плотности, нерастворимого остатка и плотности водонасыщенных пород (факторные нагрузки соответственно $0,75 ; 0,59 ; 0,54 ; 0,45$ и 0,38$)$. Так как этот фактор оказывает наибольшее влияние на магнитные свойства пород, зависящие от присутствия в породе магнитных минералов, то его можно объяснить появлением в зоне нарушения магнитных железосодержащих минералов. В осадочных породах ими являются окислы и гидроокислы железа, которые могут образоваться при вторичных процессах из немагнитных минералов или при вторичном ожелезнении пород. Влияние II фактора на повышение плотности пород свидетельствует также о привносе железосодержащих компонентов извне. Вполне закономерно влияние II фактора на повышение содержания н. о. карбонатных пород, где магнитные минералы могут содержаться в глинистой фракции в тонкорассеянном состоянии или в виде скоплений и пленок гидроокиси железа (Кобранова, 1986). III фактор контролирует изменения структурно-минералогической плотности, доломитности (факторные нагрузки $-0,79 ; 0,74$ ) и 
в меньшей степени - $x, \sigma_{\mathrm{B}}, \mathbb{W}, V_{\mathrm{B}}$ (факторные нагрузки - 0,38; 0,34; $0,26 ; 0,23)$. Исходя из этого, III фактор можно объяснить изменением карбонатного состава пород, т. е. метасоматическим замещением кальцита доломитом. Увеличение доломитности пород в зоне нарушения вызывает повышение структурно-минералогической плотности, а также других указанных выше параметров. Влияние III фактора на эффективную пористость пород объясняется тем, что в данном разрезе пористость доломитизированных пород выше, чем известняков. Связь доломитности пород с магнитной восприимчивостью можно объяснить появлением магнитных окислов железа в кристаллической решетке вторичных доломитов. Заметим, что понижающее влияние фактора эффективной пористости пород на $\sigma_{\text {в }}$ и $V_{\text {в }}$ более сильное, чем повышающее влияние II и III факторов. Таким образом, при исследовании физических свойств осадочных пород в зоне нарушения необходимо учитывать повышение эффективной пористости пород и изменение минерального состава. При учете последнего следует обращать внимание на появление окислов и гидроокислов железа. Необходимо также иметь в виду, что вторичные процессы в различной степени охватывают разные геологические слои и неравномерно проявляются в пределах одного и того же слоя.

Для объяснения влияния указанных геологических процессов на физические свойства пород в разных геологических слоях авторы исходили из параметров с наиболее высокими факторными нагрузками. Так, эффективная пористость пород $(W)$ в зоне нарушения повышается в $\mathrm{O}_{2} r g, \mathrm{O}_{2} v \ddot{a}, \mathrm{O}_{2}$ as, где возрастают визуально наблюдаемые по керну пористость и кавернозность пород; в $\mathrm{O}_{2} \mathrm{kk}$ и $\mathrm{O}_{2} k r$ пористость возрастает лишь местами; в $\mathrm{O}_{1} \mathrm{vl}$ и $\mathrm{O}_{1} 1 \mathrm{t}$ - не контролируется нарушением (рис. 3). Аналогично ведут себя в зоне нарушения и другие параметры, контролируемые I фактором, - возрастает $\eta$, н. о., уменьшается $V_{\mathrm{B}}, \sigma_{\mathrm{B}}, \varepsilon$ и $\varrho_{\mathrm{K}}$ (рис. 4,5$)$. Магнитная восприимчивость пород (рис. 6), контролируемая II фактором, повышается практически во всех слоях, кроме $\mathrm{O}_{1}$ vl и $\mathrm{O}_{1} 1 \mathrm{t}$, a остаточная намагниченность насыщения повышается лишь в породах, где визуально замечена красноцветность, обусловленная, по всей вероятности, гематитом. Структурно-минералогическая плотность (рис. 7) и доломитность пород (рис. 8) возрастают также во всех слоях, кроме $\mathrm{O}_{1} \mathrm{vl}$ и $\mathrm{O}_{1} 1 \mathrm{t}$, где контроль нарушением не отмечен.

В результате факторного анализа выяснены общие закономерности изменения физических свойств карбонатных пород в зоне нарушения III порядка: возрастание значений эффективной пористости, структурноминералогической плотности, магнитных свойств, вызванной поляризации пород; уменьшение плотности пород в естественном сложении $\left(\sigma_{\mathrm{B}}\right)$, скоростей прохождения упругих волн, кажущегося сопротивления и диэлектрической проницаемости. Можно предположить, что в зонах более крупных нарушений эти изменения будут выражены сильнее и контрастнее. Знание этих закономерностей необходимо при проектировании рационального комплекса наземных и скважинных геофизических исследований в целях выделения и изучения тектонических нарушений, выяснения их детального строения, оценки степени нарушенности горных массивов, прогнозирования карстовых явлений, планирования горных работ. 
Бронштейн $H . H$. ., Семендяев $K$. A. Справочник по математике для инженеров и учащихся вузов. М., 1986, 461.

Baхер P. М., Пуура В. А., Эрисалу Э. К. Тектоническое строение Северо-Восточной Әстонии // Тр. Ин-та геол., 1962, VII, 319-335.

Деч В. Н., Кноринг Л. Д. Нетрадиционные методы комплексной обработки и интерпретации геолого-геофизических наблюдений в разрезах скважин. Л., 1978, $49-90$.

Иёреског К. Г., Клован Д. И., Реймент Р. А. Геологический факторный анализ. Л., 1980.

Кобранова В. Н. Петрофизика. М., 1986

Пичугин Н. С., Пуура В. А., Вингиссаар П. А., Эрисалу Э. К. Региональные проявления метасоматической доломитизации в связи с тектоническими нарушениями в нижнепалеозойских отложениях Северной Прибалтики // Сов. геология, 1976, № $10,78-90$.

Прияткин А. А., Поляков Е. Е. Петрофизические исследования горных пород. Л., 1983.

Шогенова $A$. Расчленение ордовикской карбонатной толщи на Раквереском месторождении фосфоритов по данным скважинной геофизики // Изв. АН ЭССР. Геол., 1989a, 38, № 1, 10-13.

Шогенова А. Оценка нарушенности ордовикской карбонатной толщи на Раквереском месторождении фосфоритов по данным скважинной геофизики // Изв. АН ЭССР, Геол., 1989б, 38, № 3, 118-123.

Шогенова $A$. Оценка устойчивости горного массива в зоне тектонической трещиноватости на Раквереском месторождении фосфоритов по данным скважинной гео физики // Изв. АН ЭССР. Геол., 1990, 39, № 1, 1-6.

Институт геологии

Академии наук Эстонской ССР
Поступила в редакцию

13/II 1989

\section{Alla SOGENOVA, Igor TUULING}

\section{KARBONAATSETE KIVIMITE FUUSIKALISTE OMADUSTE MUUTUSED PÕHJA-EESTI LÕHEVÖÖNDIS}

Kuue puuraugu puursüdamikust võetud 140 proovis mõõdeti magnetilist vastuvõtlikkust, jääkmagnetismi, nii kuiva kui ka veega küllastunud kivimi tihedust, erikaalu ja poorsust, elastsete lainete levikukiirust nii kuivas kui ka veega küllastunud kivimis, elektrilist takistust ja indutseeritud polarisatsiooni. Nende omaduste möningad statistilised parameetrid on toodud tabelis 1. Omaduste muutlikkust vertikaalses läbilôikes illustreerivad joonised $1-3$. Faktoranalüüsi abil on välja selgitatud kolm peamist lõhevööndis füüsikaliste omaduste muutlikkust põhjustavat tegurit: kivimite kavernoossus, magnetilised komponendid ja dolomiidistumine.

\section{Alla SHOGENOVA and Igor TUULING}

\section{PHYSICAL PROPERTIES OF CARBONATE ROCKS IN THE FRACTURE AND DOLOMITIZATION ZONE (NORTH ESTONIA)}

Measurements of magnetic susceptibility, remanent magnetization, dry bulk density, wet density, grain density, effective porosity, dielectric coefficient, velocity of elastic waves in dry and saturated samples, apparent resistivity and induced polarization on 140 samples of the Ordovician carbonate rocks from six boreholes near Rakvere, North Estonia, are the basis of the statistical parameters listed in Table 1. Using the factor analysis carried out on an IMB-PC/AT three main geological factors (active openness, magnetic components and dolomitization of rocks) accounting for the variations of physical properties were brought out. 